S. J. K. Baker ; Prof. L. D. Stamp's account of the World Land Use Survey in relation to intertropical Africa; land use surveys in the Sudan (Prof. J. H. G. Lebon); the physiography of southcentral Uganda (J. W. Pallister); Kampala: planning background ( $H$. Kendall); the division pattern of African agriculture in the Nyanza Province of Kenya (H. Fearn) ; the moisture resources of Nigeria and their utilization (Prof. B. J. Garnier); the strip fields of Southern Nigeria (W. B. Morgan); some aspects of food production in the Gold Coast $(H . P$. White); two types of agriculture in West Africa: their importance from the point of view of utilization of the soil (Prof. O. Ribeiro); the population of the Gold Coast (T. F. Hilton); population patterns and migrations in Solkoto Province, Northern Nigeria (R. M. Prothero) ; some aspects of irrigated agriculture in the Northern Province of the Sudan (Ahmed El-Sayed Osman); and the functional classification of settlements (Prof. M. Boesch). The symposium provided an invaluable opportunity for exchange of views and experiences of workers in contrasted parts of tropical Africa, and Prof. Stamp pays a warm tribute to the contribution which the work of Prof. S. J. K. Baker and his staff in the Department of Geography at Makerere College made to the success of the meeting.

\section{Handbook on the International Exchange of Publications}

THE second edition of the "Handbook on the International Exchange of Publications", edited and revised by Dr. Gisela von Busse, with the collabora. tion of Dr. H. Werhahn (pp. 5707. Paris: Unesco, 1956. 1,800 fr. ; $36 s$. ; 7 dollars), differs considerably from the arrangement and lay-out of the edition distributed in 1952. All addresses and references are now grouped in Part 2, which is in two sections, the first listing exchange offers of international organizations and the second outlining national exchange activities in eighty-four countries and thirty-seven territories. This section is arranged in the form of a directory and has been brought up to date as far as 1954 where the information was available. In both these sections entries are in English, French and Spanish, but Part 1 of the handbook is printed separately in English, French and Spanish. 'The first two chapters of this part describe the different forms of exchange and the way they are handled, including new sections on the publications of international organizations and on the exchange of the Organization for European Economic Co-operation. The third chapter, dealing with conventions and agreements for the exchange of publications, includes select lists of recent bilateral agreements for the exchange of official publications and of recent bilateral cultural agreements containing clauses referring to the distribution or exchange of publications. Like the fourth chapter, dealing with transport and customs, it essentially brings up to date the chapter in the first edition dealing with this subject. The lively demand for the first edition has shown that the handbook meets a real demand, and in its new form it should meet that demand even more effectively.

\section{The Acquisition of Industrial Skills}

Experiments by W. D. Seymour on the acquisition of skills by operatives using capstan lathes showed that significantly better results were obtained with a part method of training only when the task contained elements which were perceptually stringent.
Further experiments have now been devised to show whether such improved results arose from the use of the 'progressive part' method or whether equally good results would be achieved by merely isolating the perceptually stringent elements and training these before the whole task was attempted (Occupational Psychol., 30, No. 2; April 1956). The learners were six boys and nine girls aged between $15 \frac{1}{2}$ and 18 years; all, except one, came from secondary modern schools. None had previous experience of the job chosen for the researches. They were separated at random into three groups, each of which was taught in a different way. One was shown the whole series of operations on a capstan lathe and then practised it as a whole until it could be carried out correctly in a given time. Another group, spending the same total time on learning and practising, did not tackle all the operations until it had practised first one and then a second particularly difficult operation, and could do each quickly and correctly in isolation. The third group, having the same time to learn, practised each operation separately, then combinations of some of the operations and finally the whole series. The first group was found to learn more slowly than the others; but there was no great difference in the time taken by the second and third groups. These results provide further evidence that the primary difficulty in acquiring speed skills in industrial tasks lies in the perceptual rather than the motor field.

\section{Early Palæolithic Sites of Markkleeberg, near Leipzig}

A PUblication by the American Philosophical Society on "The Lower Palæolithic Site of Markkleeberg and other Comparable Localities near Leipzig" (Trans. Amer. Phil. Soc., New Series, 45, Pt. 6 (1955); pp. 509-688 ; 2 dollars), by Rudolf Grahmann, is an account of the early Palæolithic sites of Markkleeberg that is of especial importance as the collections on which it is based were largely destroyed during the Second World. War. One can no longer consider cultures as universal, even those occurring as early as Lower Palæolithic times. Already there were provinces where different cultures existed, and a different succession came about. The coup de poing culture, for example, occurs from South Africa to Western Europe, but scarcely exists east of the Rhine, where its place is taken by various cultures the tools of which were made from flakes instead of from cores. It is a commonplace that every generation likes to disprove the ideas of their forbears, and the Rhine frontier hypothesis has been recently criticized; but the present publication entirely backs it up. Only one coup de poing has been found among thousands of tools, and it was so poorly fashioned (judging by the illustration) as to be scarcely worthy of the name. All the tools found were made on flakes, and the industries are to be classed as flake. tool industries. Rudolf Grahmann comes to the conclusion that, geologically speaking, the industries that have been found date to the Mindel-Riss and to the Riss-Würm interglaciations. The earlier of these may well be the period of the famous Mauer jaw. Almost all the artefacts found are made from Baltic flint transported to the Leipzig region by the Mindel ice. Some of the material is grey and some of it black. The collections are classified, and a number of distinct types of tools and flakes distinguished. Abouc half the publication is devoted to descriptions and to the illustrations, which are well drawn and give an 